\section{(2) OPEN ACCESS}

\title{
EULAR Points to Consider (PtC) for designing, analysing and reporting of studies with work participation as an outcome domain in patients with inflammatory arthritis
}

\author{
Annelies Boonen (D) , 1,2 Polina Putrik (D) , 1,2 Mary Lucy Marques, 3,4 \\ Alessia Alunno (1) ${ }^{5}$ Lydia Abasolo, ${ }^{6}$ Dorcas Beaton, ${ }^{7}$ Neil Betteridge, ${ }^{8}$ \\ Mathilda Bjørk (D) , ${ }^{9}$ Maarten Boers (D) , ${ }^{10}$ Boryana Boteva, ${ }^{11}$ Bruno Fautrel (D) , ${ }^{12,13}$ \\ Francis Guillemin, ${ }^{14,15}$ Elsa F Mateus, ${ }^{16,17}$ Elena Nikiphorou (D) , ${ }^{18,19}$ Márta Péntek, ${ }^{20}$ \\ Fernando Pimentel Santos, ${ }^{21,22}$ Johannes L Severens, ${ }^{23}$ Suzanne M M Verstappen, ${ }^{24,25}$ \\ Karen Walker-Bone, ${ }^{26}$ Johan Karlsson Wallman (1) , ${ }^{27,28}$ Marieke M ter Wee, ${ }^{29,30}$ \\ René Westhovens (D) , ${ }^{31,32}$ Sofia Ramiro (D) 33,34
}

\begin{abstract}
Handling editor Josef $S$
Smolen

- Additional material is published online only. To view, please visit the journal online (http://dx.doi.org/10.1136/ annrheumdis-2020-219523)

For numbered affiliations see end of article.
\end{abstract}

\section{Correspondence to}

Dr Annelies Boonen, Dapt of Internal Medicine, Div of Rheumatology, Maastricht University Medical Centre+ Internal Medicine, Maastricht 6229 HX, The Netherlands a.boonen@mumc.nl

Received 16 November 2020 Revised 21 March 2021 Accepted 23 March 2021 Published Online First 8 April 2021

\section{Check for updates}

(C) Author(s) (or their employer(s)) 2021. Re-use permitted under CC BY-NC. No commercial re-use. See rights and permissions. Published by BMJ.

To cite: Boonen $\mathrm{A}$

Putrik $\mathrm{P}$, Marques ML

et al. Ann Rheum Dis

2021:80:1116-1123.

\section{ABSTRACT}

Background Clinical studies with work participation

(WP) as an outcome domain pose particular

methodological challenges that hamper interpretation, comparison between studies and meta-analyses.

Objectives To develop Points to Consider (PtC) for design, analysis and reporting of studies of patients with inflammatory arthritis that include WP as a primary or secondary outcome domain.

Methods The EULAR Standardised Operating Procedures were followed. A multidisciplinary taskforce with 22 experts including patients with rheumatic diseases, from 10 EULAR countries and Canada, identified methodologic areas of concern. Two systematic literature reviews (SLR) appraised the methodology across these areas. In parallel, two surveys among professional societies and experts outside the taskforce sought for additional methodological areas or existing conducting/reporting recommendations. The taskforce formulated the PtC after presentation of the SLRs and survey results, and discussion. Consensus was obtained through informal voting, with levels of agreement obtained anonymously.

Results Two overarching principles and nine PtC were formulated. The taskforce recommends to align the work-related study objective to the design, duration, and outcome domains/measurement instruments of the study (PtC: 1-3); to identify contextual factors upfront and account for them in analyses (PtC: 4); to account for interdependence of different work outcome domains and for changes in work status over time (PtC: $5-7$ ); to present results as means as well as proportions of patients reaching predefined meaningful categories (PtC: 8 ) and to explicitly report volumes of productivity loss when costs are an outcome (PtC:9).

Conclusion Adherence to these EULAR PtC will improve the methodological quality of studies evaluating WP.

\section{INTRODUCTION}

Earlier diagnosis and more effective treatment strategies have improved work outcomes in patients with inflammatory arthritis (IA), including presenteeism,

\section{Key messages}

What is already known about this subject?

- Several systematic reviews of studies with work participation (WP) as a primary or secondary outcome domain have documented methodological deficiencies in the study design, analysis and reporting of results, hampering interpretation and pooling of data.

What does this study add?

- These Points to Consider (PtC) complement existing reporting guidelines, focusing on specificities of studies of patients with inflammatory arthritis that include WP as an outcome domain.

- The nine PtC address: study design, WP domains and instruments, data analysis and reporting of results.

How might this impact on clinical practice or future developments?

- Adherence to the PtC will improve the quality of studies on WP in patients with inflammatory arthritis, enabling comparisons across studies and meta-analyses.

sick leave and, to a lesser extent, employment rates. However, work participation (WP) remains lower compared with the general population. ${ }^{12}$ For patients with IA, retaining work or (re)gaining a job is relevant to their life $^{3}$ and an important treatment goal. ${ }^{4}$ From a societal perspective, participation in paid work contributes to each country's gross domestic product, and many (costly) innovations in IA can only approach cost-effectiveness when improvements in health are matched by improvements in long-term workforce participation. ${ }^{56}$

To bridge the WP gap with the general population, EULAR's current strategy states that 'by 2023, EULAR's activities and related advocacy will have 
increased participation in work by people with rheumatic and musculoskeletal diseases (RMDs) ${ }^{7}$. This requires actions within the healthcare system, but also at the level of workplaces and policies. To ensure efficient actions, high quality evidence from interventional and observational studies is needed.

WP studies face challenges that have been repeatedly highlighted in reviews of studies with WP as an outcome domain. ${ }^{89}$ Identified issues relate to heterogeneity of definitions and measures to assess WP across studies. The role of contextual factors that modify or confound the outcome is often ignored. Sample size calculation specifically for the work outcomes and other methodological aspects are neglected and reporting of outcomes is often heterogeneous. To overcome such limitations that hamper correct interpretation, guidance for conducting and reporting studies with WP as an outcome are a first step. However, no such guidelines exist for studies on WP in RMDs. ${ }^{10}$

To fill this need, a EULAR taskforce was convened. The aim of the taskforce was to formulate Points to Consider (PtC) for the design, analysis and reporting of studies in patients with IA with work as a primary or secondary outcome domain. The target users of these PtC are researchers and any other persons that plan, conduct, analyse and critically appraise studies with WP as an outcome domain in patients with IA.

\section{METHODS}

Following approval by the EULAR Executive Committee, the convenor ( $\mathrm{AB}$ ) and methodologists (SR and PP) led a taskforce guided by the 2014 updated EULAR Standardised Operating Procedures, while being also aware of the Developers of Health Research Reporting Guidelines. ${ }^{11}$

At the first meeting, the taskforce decided the focus within IA would be on rheumatoid arthritis (RA), peripheral and axial spondyloarthritis (axSpA), psoriatic arthritis and adult patients with juvenile idiopathic arthritis. The definitions of participation and employment, central concepts to the current initiative, were specified following the WHO: participation: an active engagement in a life situation; employment: being employed or selfemployed for a specific period in time (even as short as 1 day) to deliver products or services for compensation as wage, salary or in kind. ${ }^{12}{ }^{13}$ While outcomes such as employability, work (in) stability, and satisfaction with work can be relevant, they do not reflect active engagement in a production process (but the subjective experience) and thus are beyond the scope of these PtC. The taskforce also proposed to include unpaid work, as this is a relevant aspect of work participation for an even larger group of patients, and further emphasised that the PtC explicitly serve as an extension of existing reporting guidelines (eg, Consolidated Standards of Reporting Trials (CONSORT)) ${ }^{11} 1415$ and assume adherence to them. The group agreed on 24 topics of concern across several methodological areas:study design; outcome domains; outcome measurement instruments; contextual factors; data analysis, reporting of results and work productivity costs (online supplemental table S2), and decided to perform two systematic literature reviews (SLRs) and two surveys. The first SLR included prospective studies with WP as an outcome domain in patients with IA and aimed at critically appraising methodological choices and heterogeneity across studies. The second SLR was an overview of reviews addressing SLRs of studies with WP as an outcome domain in chronic diseases other than IA, and focused on finding new aspects not yet identified by the taskforce or in IA studies. SLR findings have been published in an accompanying paper. ${ }^{16}$ The first survey was conducted among professional organisations to identify other similar (unpublished) recommendations/guidelines beyond rheumatology. The second survey was conducted among experts on WP to identify other relevant methodological areas/topics (online supplemental tables S1 and S2). The SLRs and surveys resulted in 16 topics within four areas ${ }^{1}$ : study design, ${ }^{2}$ work outcome domains and measurement instruments, ${ }^{3}$ data analysis and $^{4}$ reporting of results.

At the second meeting, the taskforce members formulated the PtC based on evidence from the two SLRs, findings of the surveys and expert opinion of taskforce members following a process of discussion and voting. Consensus was accepted if $>75 \%$ of the members voted in favour of the $\mathrm{PtC}$ in the first (or $>67 \%$ and $>50 \%$ in a second and third) round. After the meeting, the levels of evidence derived from the SLRs following the standards of the Oxford Center for Evidence Based Medicine were added to each of the recommendations. ${ }^{17}$ Finally, each taskforce member anonymously indicated the level of agreement $(\mathrm{LoA})$ via email (numeric rating scale ranging from $0=$ 'do not agree at all' to $10=$ 'fully agree'). The mean and SD of the LoA as well as the percentage of taskforce members with an agreement $\geq 8$ are presented.

Based on the gaps in evidence and the issues of controversy, a research agenda was formulated. The final manuscript was approved by the EULAR Executive Committee.

\section{RESULTS}

The taskforce agreed on two overarching principles and nine PtC (table 1).

\section{Overarching principles}

1. WP is important for people with inflammatory arthritis, their families and society as a whole.

2. There are unique methodological aspects around designing, analysing and reporting studies with WP as a primary or secondary outcome that require specific attention.

\section{Points to consider}

1. In studies with WP as primary or secondary outcome the study design, the study duration and the choice of WP outcome domains and measurement instruments should be considered in relation to the work-related study objective.

WP studies can serve a variety of objectives, such as developing risk-identification tools to predict adverse work outcomes, proving effectiveness of pharmacological or non-pharmacological interventions, assessing the impact of costs of work productivity loss in economic evaluations and so on. While each study objective requires a specific design, non-pharmacological interventions pose additional challenges related to contamination of the intervention, problems with double blinding, difficulty controlling for cointerventions, and long lag times for some outcomes. For these studies, strengths and weaknesses of various semiexperimental study designs should be weighted. ${ }^{18}$ Next, careful consideration should be given to the target population as different WP outcomes may apply to distinct (sub)populations. For example, when the aim is to assess the impact of a certain treatment on employment, all persons below the age of retirement are the target, whereas for a study on the impact of treatment on sick leave, employed persons are the target. Additionally, some studies might wish to target specific patients, for example, those with short disease duration; with low educational level; doing manual work; or with low self-management skills, requiring specification of eligibility criteria. Further, interpretation of the work outcome(s) depends on the participation rate in 
Table 1 EULAR Points to Consider when designing, analysing and reporting studies with work participation as a primary or secondary outcome domain: LoE, SOR and LoA

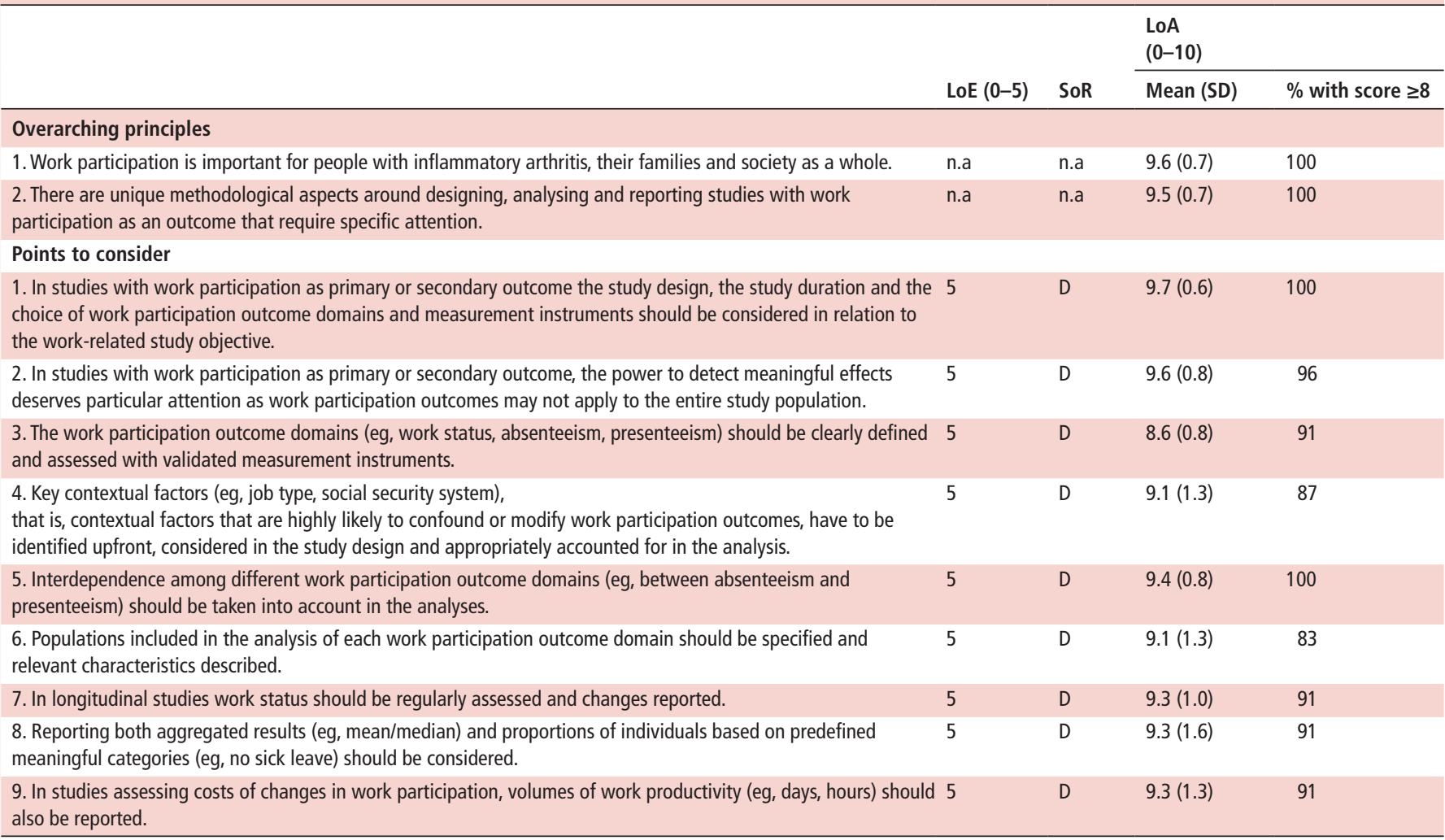

LoE: 1-5 (5 indicating evidence from expert committee reports or opinions and/or clinical experience of respected authorities, and/or evidence extrapolated for quasi experimental or descriptive studies) ${ }^{17}$; SoR: A to D (D indicating troublingly inconsistent or inconclusive studies of any level) ${ }^{18}$ LoA, level of agreement; LoE, level of evidence; n.a, not applicable; SoR, strength of recommendation.

the general population. It is useful to reflect in the design phase whether population benchmarks for sick leave, work disability and employment status are important and feasible. Crucial in any design is the choice of the outcome domain(s) of interest and their match with the objective and study duration. While changes in presenteeism and sick leave can occur over short periods in time, longer term sick leave and, in particular, work disability require longer observation periods. Additionally, the taskforce urges researchers to ensure alignment of the frequency of assessment of WP outcomes to the recall of the measurement instruments and the study objective. For example, in a 24 -week randomised controlled trial with a rapidly acting intervention, assessment of sick leave in the past 7 days (eg, using Work Productivity and Activity Impairment Index (WPAI) ${ }^{16} 1920$ at baseline and endpoint is useful, as the interest is to assess change in sick leave on a group level. Alternatively, when cumulative days of sick leave over time are of interest in an observational study with long follow-up, the recall (eg, past 3 months) should fit the duration of the inter-assessment period (in casu 3 months). Importantly, the taskforce emphasised that for studies with WP as a primary outcome, the choices on the issues above should be 'justified', not just 'considered'.

2. In studies with WP as primary or secondary outcome, the power to detect meaningful effects deserves particular attention as WP outcomes may not apply to the entire study population.

The majority of WP studies include work as a secondary objective. ${ }^{16}$ As work outcomes often relate to a sub-sample of the population for which the initial sample size was calculated (eg, 18-64 years when work status is the outcome of interest; those employed when sick leave or presenteeism are studied), the number of patients eligible for the work outcome analyses drops, likely reducing the power to detect differences between groups. Researchers should consider this when designing the study or selecting a dataset.

3. The WP outcome domains (eg, work status, absenteeism, presenteeism) should be clearly defined and assessed with validated measurement instruments.

Heterogeneity or lack of definitions of the WP outcome domains are an important cause of incomparability and a risk for misinterpretation of findings across studies. While for some commonly used (sub)-domains (eg, employment) formal definitions have been proposed, operationalisation varies greatly across administrative entities (countries, regions, states, etc). As a consequence, researchers may have good reasons to use a specific or adjusted definition (eg, self-reported vs formal work disability). Nevertheless, a clear description of each WP outcome domain under study is warranted, and definitions should fit the research objective but also strike a balance between local usefulness and generalisability of the study findings (table 2).

To support measurement of WP outcome domains, Outcome Measures in Rheumatology (OMERACT) continuously updates the validity of self-reported instruments to assess presenteeism. ${ }^{21}$ The taskforce specified that for presenteeism the study objective should guide the choice between single-item and multiitem/multidimensional instruments. Of note, specific aspects of measurement instruments including the recall period, disease attribution or the anchors for presenteeism or absenteeism (compared with your own best or to an average worker) are not specifically addressed in the above assessments of validity. 
Table 2 Glossary of terms relevant for the current Points to Consider

\begin{tabular}{|c|c|c|}
\hline Term & Source & Definition \\
\hline Work participation & ICF & Active engagement in paid or unpaid work. \\
\hline \multirow[t]{2}{*}{ Contextual factor } & ICF & $\begin{array}{l}\text { In the bio-psycho-social framework of health } \\
\text { contextual factors refer to variables that are part of the environment of the individual (eg, social attitudes, architectural } \\
\text { characteristics, legal and social structures, as well as climate, etc) or characterise the individual him/herself (eg, gender, age, coping, } \\
\text { lifestyle, social background, education, profession, past and current experiences). They influence occurrence and course of disease } \\
\text { and determine how illness and disability is experienced by the individual. }\end{array}$ \\
\hline & OMERACT & $\begin{array}{l}\text { In the framework of outcome assessment, contextual factors are variables that are not the outcome of the study, but need to be } \\
\text { recognised to understand the study results. They also include confounders and effect modifiers. } \\
\text { They can be measurement affecting, outcome influencing or effect modifying. }\end{array}$ \\
\hline Employment & ILO/WHO & $\begin{array}{l}\text { An agreement to produce goods or services for a specific period in time for compensation by a salary, a wage or in kind. Different } \\
\text { types of employment exist, among which is self-employment. }\end{array}$ \\
\hline Part-time employment & ILO/WHO & When the hours of work are less than the 'normal' hours of work of a comparable full-time employment. \\
\hline Sick leave & WIKI & Time off from work that workers can use to stay home to address their health and safety needs without losing pay. \\
\hline Paid sick leave & ILO/WHO & $\begin{array}{l}\text { A statutory requirement in many nations or organisations that comprise (universal) income substitutions for persons that have } \\
\text { temporary time off from the employment contract due to illness or disability. } \\
\text { Against this background sick leave consists of two components: leave from work due to sickness and cash benefits that replace the } \\
\text { wage during the time of sick leave. }\end{array}$ \\
\hline Presenteeism & Various & $\begin{array}{l}\text { Refers to: } \\
\text { 1. The behaviour of attending (paid) work while being ill. } \\
\text { 2. The level of influence on the work process (productivity, efficiency, performance) experienced by the worker (ability, difficulty). }\end{array}$ \\
\hline Work productivity & & The amount of goods and services produced in a specific time frame/period in time. \\
\hline Unemployment & ILO/WHO & Not being employed but looking for an employment. \\
\hline Work disability & ILO & $\begin{array}{l}\text { When an individual is unable to perform work-related tasks due to physical or mental impairments or disability. } \\
\text { In many constituencies definitions of disability are identical with an administrative act of recognising a disability. } \\
\text { This recognition as disabled becomes a prerequisite for the claiming of support on the basis of a physical or mental limitation or for } \\
\text { litigation under an antidiscrimination law. } \\
\text { Such support can comprise provisions for rehabilitation, special education, retraining, privileges in the securing and preserving of a } \\
\text { place of employment, guarantee of subsistence through income, compensation payments and assistance with mobility, etc. } \\
\text { Virtually every existing definition of disability thus mirrors } \\
\text { a legal system and draws its meaning from this system. } \\
\text { It is also a highly heterogeneous concept, making the search for a homogeneous definition a virtually impossible task. }\end{array}$ \\
\hline Decent work & ILO & $\begin{array}{l}\text { Decent work involves opportunities for work that are productive and deliver a fair income, security in the workplace and social } \\
\text { protection for families, better prospects for personal development and social integration, freedom for workers to express concerns, } \\
\text { organise and participate in the decisions that affect their lives and equality of opportunity for all women and men. }\end{array}$ \\
\hline Unpaid work & WHO & $\begin{array}{l}\text { Unpaid work activities include own-use production of services and volunteer work in households or organisations producing } \\
\text { services for others. }\end{array}$ \\
\hline
\end{tabular}

Regarding recalling information, there is evidence that recall beyond 3 months for sick leave becomes inaccurate and that patients prefer a recall period of 1-4 weeks for presenteeism; patients suggests 4 weeks is more representative. ${ }^{22}{ }^{23}$ Attribution to overall health (opposed to IA-related) is preferred, as patients struggle to attribute restrictions to arthritis vs overall health, and it allows benchmarking with the general population. Of note, in several countries regulations are in place to link healthcare data to social security databases that include information on sick leave and work disability. While avoiding non-response and recall bias, such linkage of data is not without challenges. A pertinent example is that registration only starts when sick leave exceeds a number of prespecified days.

4. Key contextual factors (eg, job type, social security system), that is, contextual factors that are highly likely to confound or modify WP outcomes, have to be identified upfront, considered in the study design, and appropriately accounted for in the analysis.

There is ample evidence associating work-related environmental and personal contextual factors to WP outcomes, either as effect modifiers, or other types of covariates. ${ }^{24}$ Contextual factors can be facilitators or barriers for WP. ${ }^{25}$ For example, manual workers experience more impact from axSpA on presenteeism, but also experience more beneficial effect of bDMARDs on presenteeism. ${ }^{26}$ Country of residence (likely reflecting social security regulations, including income substitution) is another contextual determinant of variation in employment and sick leave rates across countries, ${ }^{27} 28$ and may cause effect modification of interventions. ${ }^{29}$ OMERACT proposed a classification of 12 contextual factor domains potentially relevant for WP outcomes $^{3031}$ (table 3). The choice of contextual factors, as well as the methodological approach to account for them (eg, stratification, post hoc analyses) should be prespecified in the study protocols. Whereas contextual factors refer-according to some definitions - to factors outside the disease (eg, job type), ${ }^{32}$ also disease-related factors (eg, early vs established disease; type of joints involved) or factors within the work outcome continuum (eg, being partly work disabled) can be equally relevant as effect modifiers or covariates. On this line, jobs requiring hand dexterity might affect work outcomes more importantly in patients with small joint involvement compared with those with only back manifestations.

5. Interdependence among different WP outcome domains (eg, between absenteeism and presenteeism) should be taken into account in the analyses.

WP presents a continuum of subdomains which are dependent on each other, and may compete over time. For example, formal work disability cannot occur anymore after early retirement from paid work; and presenteeism cannot occur when a person is on sick leave (ie, absent form work). Dependency of outcome 
Table 3 Proposal for classification of contextual factors relevant for studies with work participation as an outcome domain. Contextual factors can be facilitators or barriers

\begin{tabular}{ll}
\hline Personal contextual factors & Environmental contextual factors \\
\hline Health* & Nature of work \\
\hline Pain & Physical/mental demands \\
\hline Fatigue & Job autonomy \\
\hline Physical function & Workplace support/barriers \\
\hline Demographics & Assistance by coworkers \\
\hline Age and gender & Attitude of employer \\
\hline Education & Workplace organisation \\
\hline Economic need & Team dynamics at work \\
\hline Income needs & Compensation of absence (eg, \\
\hline Quality of benefits & replacement practices) \\
\hline Personal appraisal of work & Workplace accommodation \\
\hline Job satisfaction & Adaptive devices \\
\hline Career perspectives & Modified hours/duties \\
\hline Skills and abilities & Economic climate/labour regulations \\
\hline Work-efficacy & Income compensation \\
\hline Coping & Employment opportunities \\
\hline Work-life balance & Workplace accommodation \\
\hline Competing social roles & Adaptive devices \\
\hline Quality of leisure & Modified hours/duties \\
\hline & Non-workplace support/barriers \\
\hline & Support from family \\
\hline & Task assistance at home \\
\hline
\end{tabular}

* In the setting of clinical studies, health factors are relevant to interpret the study results and (contrary to the International Classification of Functioning, Disability and Health (ICF) definition) considered to represent personal contextual factors. In the ICF classification, contextual factors are by definition external to health factors. In the Outcome Measures in Rheumatology methodological definition, health factors can be covariates (effect modifiers, confounders).

domains can explain why an intervention that markedly reduces sick leave days, can lead to an increase in presenteeism. To account for dependencies, it is advised to always collect information on the (sub-)domains that are hierarchically higher (presenteeism depends on sick leave, sick leave depends on work status) on the work ability/productivity continuum, or conceptually related to the outcome (sub)-domain of interest (eg, absenteeism and presenteeism; retiring early or becoming work disabled). Authors need to report whether and how they dealt with this dependency. ${ }^{1633}$ For example, the WPAI deals formally with this issue by combining presenteeism and absenteeism into an overall work impairment scale. ${ }^{34}$

6. Populations included in the analysis of each WP outcome domain should be specified and relevant characteristics described.

WP outcomes are often performed in subsamples of the original study. ${ }^{16}$ For example, a model exploring risk factors for work disability is to be analysed in the at-risk population below retirement age (usually 18-64 years old), while a model on risk factors for long-term sick leave or presenteeism addresses the employed population. Especially when measurement instruments report impact on paid as well as unpaid work (eg, WPAI), numbers and details of the employed and unemployed patients should be provided. ${ }^{16}$ To facilitate the correct interpretation of the output of the analyses, the baseline demographic and disease characteristics of each (sub)-group should be described.

7. In longitudinal studies work status should be regularly assessed and changes reported.
Given the chronic, progressive character of IA, longitudinal studies are encouraged to assess changes in WP. Those changing their work status (especially, becoming work disabled) are likely prognostically different from the rest of the population. For example, if an improvement in sick leave of employed persons with early RA was observed over time, this may partly be due to patients with the highest disease impact-and thus sick leavebecoming work disabled over time. Therefore, in longitudinal studies transitions should be described, and either accounted for in analyses or discussed when interpreting the results.

8. Reporting both aggregated results (eg, mean/median) and proportions of individuals based on predefined meaningful categories (eg, no sick leave) should be considered.

In addition to mean and median values of continuous measures (such as sick leave days, level of presenteeism), also the proportion of patients attaining a specific meaningful (change in) outcome adds to insight of the WP outcome. For example, as presenteeism and absenteeism have often a skewed (or zero-inflated) distribution, it is informative to present also the proportion of patients that had no sick leave or presenteeism. Meaningful categorisation can also be based on what is used by the social security system (eg, proportion with specific number of sick leave days). For presenteeism, work has been done on the minimally important difference, but data do not seem robust and more work is needed before a generalisable threshold is proposed. $^{35}$

9. In studies assessing costs of decreased WP, volumes of work productivity loss (eg, days, hours) should also be reported.

Productivity costs are a relevant aspect of WP but valuing loss of productivity in monetary terms (ie, costing) is complex and beyond the expertise of this taskforce. Nevertheless, the taskforce wanted to highlight a basic principle that should be fulfilled when researchers aim to proceed towards calculating costs of productivity loss. In any cost study, authors should first collect/report the natural volumes of production loss (usually time; days/hours) before providing the costestimates. In view of poor agreement between self-reported productivity loss while at work (presenteeism) and actual productivity loss, presenteeism costs should be considered in sensitivity analyses only. ${ }^{16}$

\section{Research agenda}

Areas or topics that were considered important by the taskforce experts but for which the level of uncertainty was too high to formulate a PtC were included in a research agenda (table 4).

\section{DISCUSSION}

Assessment of WP as an outcome domain in clinical studies has specific methodological challenges. The nine $\mathrm{PtC}$ aim to improve the quality of interventional and non-interventional studies and should eventually contribute to improving WP for patients with IA. Specifically, adherence to these methodological considerations should lead to unbiased results and facilitate meta-analyses.

A clear study objective constitutes a first and critical step of any WP outcome study, as it determines the target population, the outcome domains, the study duration, the frequency with which outcomes should be assessed in relation to the recall of the measurement instrument, and, finally, the contextual factors that should be accounted for. In addition, in the analysis and report the interdependence (and competition) between WP outcomes should receive specific attention. While these individual topics seem basic epidemiological knowledge, and some of them are (implicitly) part of the CONSORT $^{1536}$ and Strengthening the Reporting of Observational Studies in Epidemiology ${ }^{14}$ statements, they accumulate in work outcome studies and are frequently ignored in existing studies. ${ }^{16}$ 
Table 4 Research agenda

\begin{tabular}{|c|c|}
\hline Topic & Questions \\
\hline Unpaid work participation & $\begin{array}{l}\text { How can unpaid work participation as an outcome domain be defined? } \\
\text { Which measurement instruments are valid to assess the domain unpaid work (in IA)? }\end{array}$ \\
\hline Contextual factors & $\begin{array}{l}\text { How to measure contextual factor domains relevant for work participation? } \\
\text { What is the operational definition of a 'key' contextual factor } \\
\text { (eg, if it has proven to behave consistently as: } \\
\text { (a) Relevant effect modifier of interventions in work outcome studies, or (b) Consistently } \\
\text { relevant covariate of work outcomes } \\
\text { in observational studies.)? } \\
\text { To what extent are contextual factors specific to certain setting } \\
\text { (eg, specific for a certain outcome are a certain intervention)? }\end{array}$ \\
\hline Interdependence and integration of the work outcome domains & $\begin{array}{l}\text { How to deal with interdependence or competition between work participation outcomes } \\
\text { (work status, absenteeism and presenteeism)? } \\
\text { Can we redesign work outcome measurement that integrates work disability, } \\
\text { absenteeism and presenteeism? }\end{array}$ \\
\hline Analyses of skewed data & $\begin{array}{l}\text { What is the comparative accuracy of methods to deal with different types of skewed or } \\
\text { zero-inflated data? }\end{array}$ \\
\hline Decent work and healthy workplaces & $\begin{array}{l}\text { What is a healthy work and what is a healthy workplace? } \\
\text { How can we measure it? } \\
\text { What are the health effects of not taking sick leave and not adjusting productivity while } \\
\text { at work (presenteeism)? }\end{array}$ \\
\hline
\end{tabular}

$\mathrm{IA}$, inflammatory arthritis.

The taskforce identified and discussed some areas or topics where no consensus could be reached due to lack of evidence and placed these in the research agenda. In the first taskforce meeting, it was proposed to broaden the scope of $\mathrm{PtC}$ to studies with unpaid work as an outcome domain clearly impacted by IA. However, the absence of appropriate definitions and absence of evidence from both SLRs, led the taskforce to urgently recommend more research focus on unpaid work. The lack of evidence on specific methodological issues (eg, contextual factors, skewness or interdependence of outcomes) prevented more specific statements on these issues, which were also added to the research agenda.

The taskforce would like to emphasise that while important, improvement of WP, employment, reduced sick leave or presenteeism should never be reached at the expense of long-term health or even life satisfaction. Rather, the final goal should be to support patients in healthy and sustainable work, and days off work or adjustments in work productivity can be tools to reach this goal. Defining and measuring 'healthy and sustainable work' is added as a challenge to our research agenda. Reaching these goals will not only depend on efforts within the healthcare system to support patients to stay at work but will also require supportive employers, behavioural changes towards workers with a chronic disease and policies for healthy workplaces and support systems for persons with chronic diseases. This underpins the urgency of EULAR's strategic goal to improve work circumstances of people with RMDs. ${ }^{7}$ Patient representatives found it challenging to take an active role in the discourse of complex methodological issues, but were instrumental in reinforcing the discussions on unpaid work, healthy work and context, ensuring these aspect were included in statements or research agenda.

In conclusion, guidance is now available to improve interpretation and comparison of studies in IA with WP as an outcome domain. We expect the PtC will facilitate improved conduct of WP outcome studies.

\footnotetext{
Author affiliations

${ }^{1}$ Division of Rheumatology, Maastricht University Medical Centre+ Internal Medicine, Maastricht, The Netherlands

${ }^{2}$ Universiteit Maastricht Care and Public Health Research Institute, Maastricht, The Netherlands

${ }^{3}$ Rheumatologist, Leiden University Medical Center, Leiden, The Netherlands

${ }^{4}$ Rheumatology, Centro Hospitalar e Universitario de Coimbra EPE, Coimbra, Portugal
}

${ }^{5}$ Rheumatology Unit, University of Perugia Department of Medicine, Perugia, Italy ${ }^{6}$ Department of Rheumatology, Instituto de Investigation Sanitaria San Carlos, Hospital Clinico Universitario San Carlos, Madrid, Spain

${ }^{7}$ Mobility Program Clinical Research Unit, St Michael's Hospital Li Ka Shing

Knowledge Institute, Toronto, Ontario, Canada

${ }^{8}$ Neil Betteridge Associates, London, UK

${ }^{9}$ Pain and Rehabilitation Center, and Department of Health, Medicine and Caring Sciences, Linköping University, Linkoping, Sweden

${ }^{10}$ Department of Epidemiology and Data Science; Amsterdam Rheumatology and Immunology Center, Amsterdam University Medical Centers, Vrije Universiteit,

Amsterdam, Amsterdam, The Netherlands

${ }^{11}$ Patients with Arthritis and Rheumatism (PARE) working group, European League Against Rheumatism, Zurich, Switzerland

${ }^{12}$ PEPITES teams, Pierre Louis Institute for Epidemiology and Public Health, Inserm UMR 1136, Paris, France

${ }^{13}$ Rheumatology Dept, Pitié Salpetriere Hospital, Sorbonne University / Assistance Publique- Hôpitaux de Paris, Paris, Fance

${ }^{14}$ APEMAC, Université de Lorraine, Nancy, France

${ }^{15} \mathrm{CIC}$ Epidémiologie Clinique, CHRU Nancy, Inserm, Université de Lorraine, Nancy, France

${ }^{16}$ Portuguese League Against Rheumatic Diseases (LPCDR) and Comprehensive

Health Research Centre (CHRC), Lisbon, Portugal

${ }^{17}$ People with Arthritis and Rheumatism (PARE), European League Against

Rheumatism, Zurich, Switzerland

${ }^{18}$ Centre for Rheumatic Diseases, King's College of London, London, UK

${ }^{19}$ Rheumatology Department, King's College Hospital, London, UK

${ }^{20}$ Health Economics Research Center, University Research and Innovation Center,

Óbuda University, Budapest, Hungary

${ }^{21}$ Rheumatology Department, Centro Hospitalar de Lisboa Ocidental EPE Hospital de Egas Moniz, Lisboa, Portugal

${ }^{22}$ NOVA Medical School, Lisboa, Portugal

${ }^{23}$ Erasmus School of Health Policy \& Management and iMTA, Institute for

Medical Technology Assessment, Erasmus University Rotterdam, Rotterdam, The

Netherlands

${ }^{24}$ Centre for Epidemiology Versus Arthritis, Centre for Musculoskeletal Research, Faculty of Biology, Medicine and Health, The University of Manchester, Manchester, UK

${ }^{25}$ Manchester University NHS Foundation Trust, Manchester Academic Health Science Centre, NIHR Manchester Biomedical Research Centre, Manchester, UK

${ }^{26}$ MRC Versus Arthritis Centre for Musculoskeletal Health and Work, MRC Life course

Epidemiology Unit, Southampton General Hospital, Southampton, UK

${ }^{27}$ Department of Clinical sciences, Lund University, Lund, Sweden

${ }^{28}$ Department of Rheumatology, Skåne University Hospital, Lund, Sweden

${ }^{29}$ Department of Epidemiology and Data Science, Amsterdam Public Health,

Amsterdam UMC, Vrije Universiteit Amsterdam, Amsterdam, The Netherlands

${ }^{30}$ Department of Rheumatology and immunology, AI\&l, Amsterdam UMC, Vrije

Universiteit Amsterdam, Amsterdam, The Netherlands

${ }^{31}$ Dept of Rheumatology, KU Leuven University Hospitals Leuven, Leuven, Belgium 
${ }^{32}$ Skeletal Biology and Engineering Research Centre, KU Leuven Department of Development and Regeneration, Leuven, Belgium

${ }^{33}$ Rheumatology, Leiden University Medical Center, Leiden, The Netherlands

${ }^{34}$ Rheumatology, Zuyderland Medical Centre Heerlen, Heerlen, The Netherlands

Twitter Neil Betteridge @Neil_Betteridge and Elena Nikiphorou @ElenaNikiUK

Acknowledgements We wish to express our gratitude to all experts participating in the survey, several of which consented to be included formally in the acknowledgements: Ailsa Bosworth, MBE, National Patient Champion, National Rheumatoid Arthritis Society, UK; Ann Bremander, PT, PhD, Department of Regional Health Research, University of Southern Denmark, Odense, Denmark and Section of Rheumatology, Department of Clinical Sciences, Lund University, Lund, Sweden; Arthur Kavanaugh, MD, Professor of Medicine, University of California, San Diego, USA; Atul Deodhar, MD, Professor of Medicine, Oregon Health \& Science University, Portland, USA; Casper Webers, MD, Department of Internal Medicine, Division of Rheumatology, Maastricht University Medical Center, Maastricht, the Netherlands; Désirée van der Heijde, MD, PhD, Department of Rheumatology, Leiden University Medical Center, Leiden, The Netherlands; Florian Berghea, Associate Professor Carol Davila University of Medicine and Pharmacy, Bucharest, Romania; Imre Boncz, MD, MSc, PhD, Institute for Health Insurance, Faculty of Health Sciences, University of Pécs, Pécs, Hungary; Ingemar Petersson, MD, PhD, Head of ResearchSkåne University Care Trust (Lund and Malmö), Sweden; Jette Primdahl, Professor, Danish Hospital for Rheumatic Diseases, Sonderborg, Denmark and Department of Regional Health Research, University of Southern Denmark, Odense, Denmark; Kari Puolakka, MD, PhD, Terveystalo, Lappeenranta, Finland; Karthik Mani, OTD, OTR/L, National Board for Certification in Occupational Therapy (NBCOT), Maryland USA; Katie Druce, MSc, PhD, Centre for Epidemiology Versus Arthritis, Division of Musculoskeletal and Dermatological Sciences, University of Manchester, UK; Laszlo Czirjak, PTE, Department of Rheumatology and Immunology, Medical School, University of Pécs, Pécs, Hungary; László Gulácsi, MD, MSc, PhD, Department of Health Economics, Corvinus University of Budapest, Hungary; Lennart R. A. van der Burg, MD, Department of General Practice and Care and Public Health Research Institute (CAPHRI), Maastricht University, Maastricht, The Netherlands; Manouk de Hooge, PhD, Department of Rheumatology, Ghent University Hospital and VIB Center of Inflammation Research, Ghent University, Ghent, Belgium; Michiel Reneman, $\mathrm{MD}_{\text {, }}$ PhD, University Medical Center Groningen, The Netherlands; Miranda van Lunteren, MSc, Leiden University Medical Center, Leiden, the Netherlands; Pál Géher, MD, Semmelweis Univ. Budapest, Hungary; Peter C Taylor MA, PhD, FRCP, University of Oxford, UK; Peter V Balint, MD, PhD, FRCP (Glasgow), 3rd Rheumatology Department, National Institute of Rheumatology and Physiotherapy Budapest, Hungary; Ross Wilkie, Senior Lecturer in Public health and Epidemiology, School for Primary, Community and Social Care, Keele University, Keele, Staffordshire, UK; Yeliz Prior, PhD, University Salford and Advanced Clinical Specialist Occupational Therapist at the Mid Cheshire NHS Hospitals Trust, Crewe, UK; Zoltan Szekanecz, MD PhD, Division of Rheumatology, University of Debrecen Faculty of Medicine, Debrecen, Hungary. We are very grateful to Louise Falzon for the literature searches that served the systematic literature reviews.

Contributors $A B, S R, P P, M L M$ and $A A$ designed the study; MLM and AA collected the data; all authors participated in the interpretation of the data; $A B, S R, P P, M L M$ and AA prepared the manuscript; all authors critically appraised and approved the final manuscript.

Funding This study was funded by European League Against Rheumatism (EPI021) SMMV is supported by the NIHR Manchester Biomedical Research Centre and Versus Arthritis (grant number 20380).

Competing interests $A B$ : research grants from Abbvie and Celgene and honoraria for consultancy or speakers honoraria from UCB, Biogen, Sandoz, Eli Lilly and Galapagos (all to her department); EN has received speaker honoraria/participated in advisory boards for Celltrion, Pfizer, Sanofi, Gilead, AbbVie and Lilly; FPS: research grant from AbbVie, Novartis; consultancy or speaking fees: AbbVie, Angelini, AstraZeneca, Biogen, Eli Lilly, Laboratórios Vitória, MSD, Novartis, Tecnimed, UCB; SR: research grant from MSD; consultancy or speaking fees: AbbVie, Eli Lilly, MSD, Novartis, Sanofi, UCB; JKW: consultancy fees from Celgene, Eli Lilly, Novartis; RW: consultancy and speakers bureau Celltrion and Galapagos/Gilead.

Patient consent for publication Not required.

Provenance and peer review Not commissioned; externally peer reviewed.

Data availability statement Data sharing not applicable as no datasets generated and/or analysed for this study. No datasets were generated and/or analysed for this study.

Supplemental material This content has been supplied by the author(s). It has not been vetted by BMJ Publishing Group Limited (BMJ) and may not have been peer-reviewed. Any opinions or recommendations discussed are solely those of the author(s) and are not endorsed by BMJ. BMJ disclaims all liability and responsibility arising from any reliance placed on the content. Where the content includes any translated material, BMJ does not warrant the accuracy and reliability of the translations (including but not limited to local regulations, clinical guidelines, terminology, drug names and drug dosages), and is not responsible for any error and/or omissions arising from translation and adaptation or otherwise.

Open access This is an open access article distributed in accordance with the Creative Commons Attribution Non Commercial (CC BY-NC 4.0) license, which permits others to distribute, remix, adapt, build upon this work non-commercially, and license their derivative works on different terms, provided the original work is properly cited, appropriate credit is given, any changes made indicated, and the use is non-commercial. See: http://creativecommons.org/licenses/by-nc/4.0/.

\section{ORCID iDs}

Annelies Boonen http://orcid.org/0000-0003-0682-9533

Polina Putrik http://orcid.org/0000-0002-9342-1861

Alessia Alunno http://orcid.org/0000-0003-1105-5640

Mathilda Bjørk http://orcid.org/0000-0002-1607-187X

Maarten Boers http://orcid.org/0000-0002-6969-283X

Bruno Fautrel http://orcid.org/0000-0001-8845-4274

Elena Nikiphorou http://orcid.org/0000-0001-6847-3726

Johan Karlsson Wallman http://orcid.org/0000-0002-4915-2924

René Westhovens http://orcid.org/0000-0002-3432-3073

Sofia Ramiro http://orcid.org/0000-0002-8899-9087

\section{REFERENCES}

1 Eriksson JK, Neovius M, Bratt J, et al. Biological vs. conventional combination treatment and work loss in early rheumatoid arthritis: a randomized trial. JAMA Intern Med 2013;173:1407-14.

2 Webers C, Vanhoof L, van Genderen S, et al. Employment and the role of personal factors among patients with ankylosing spondylitis: a Dutch cross-sectional casecontrol study. RMD Open 2018;4:e000680.

3 Boonen A, Boone C, Albert A, et al. Understanding limitations in at-work productivity in patients with active ankylosing spondylitis: the role of work-related contextual factors. J Rheumatol 2015;42:93-100

4 Strand V, Wright GC, Bergman MJ, et al. Patient expectations and perceptions of Goal-setting strategies for disease management in rheumatoid arthritis. J Rheumatol 2015:42:2046-54.

5 van der Velde G, Pham Ba', Machado M, et al. Cost-Effectiveness of biologic response modifiers compared to disease-modifying antirheumatic drugs for rheumatoid arthritis: a systematic review. Arthritis Care Res 2011;63:65-78.

6 Boonen A, Webers C. Economic Evaluations in Axial Spondy loarthritis. In: Mease P, Khan M, eds. Axial spondyloarthritis. Paperback ISBN: 9780323568005 , eBook ISBN: 9780323568012. Elsevier, 2019.

7 EULAR. EULAR strategy 2023, 2020. Available: https://www.eular.org/eular_strategy_ 2018.cfm

8 van der Burg LRA, Ter Wee MM, Boonen A. Effect of biological therapy on work participation in patients with ankylosing spondylitis: a systematic review. Ann Rheum Dis 2012:71:1924-33.

9 ter Wee MM, Lems WF, Usan $H$, et al. The effect of biological agents on work participation in rheumatoid arthritis patients: a systematic review. Ann Rheum Dis 2012;71:161-71.

10 Equator network. Enhancing the quality and transparency of health research, 2020. Available: https://www.equator-network.org/

11 Moher D, Schulz KF, Simera I, et al. Guidance for developers of health research reporting guidelines. PLoS Med 2010;7:e1000217.

12 ILO. Employment by status in employment, 2020. Available: https://www.ilo.org/ ilostat-files/Documents/description_STE_EN.pdf

13 Institut national de la statistique et des etudes economiques. Employement (ILO), 2020. Available: https://www.insee.fr/en/metadonnees/definition/c1159

14 von Elm E, Altman DG, Egger M, et al. The strengthening the reporting of observational studies in epidemiology (STROBE) statement: guidelines for reporting observational studies. J Clin Epidemiol 2008;61:344-9.

15 Schulz KF, Altman DG, Moher D, et al. Consort 2010 statement: updated guidelines for reporting parallel group randomised trials. J Clin Epidemiol 2010;63:834-40.

16 Marques ML, Alunno A, Boonen A, et al. Methodological aspects of design, analysis and reporting of studies with work participation as an outcome domain in patients with inflammatory arthritis: results of two systematic literature reviews informing EULAR points to consider. RMD Open 2021:7:e001522.

17 Oxford centre for evidence-based medicine. levels of evidence (updated in 2012), 2009. Available: https://www.cebm.ox.ac.uk/resources/levels-of-evidence/oxfordcentre-for-evidence-based-medicine-levels-of-evidence-march-2009

18 Schelvis RMC, Oude Hengel KM, Burdorf A, et al. Evaluation of occupational health interventions using a randomized controlled trial: challenges and alternative research designs. Scand J Work Environ Health 2015:41:491-503.

19 Reilly MC, Gooch KL, Wong RL, et al. Validity, reliability and responsiveness of the work productivity and activity impairment questionnaire in ankylosing spondylitis. Rheumatology 2010;49:812-9.

20 Zhang W, Bansback N, Boonen A, et al. Validity of the work productivity and activity impairment questionnaire--general health version in patients with rheumatoid arthritis. Arthritis Res Ther 2010;12:R177. 
21 Beaton DE, Dyer S, Boonen A, et al. OMERACT filter evidence supporting the measurement of At-work productivity loss as an outcome measure in rheumatology research. J Rheumatol 2016;43:214-22.

22 Severens JL, Mulder J, Laheij RJ, et al. Precision and accuracy in measuring absence from work as a basis for calculating productivity costs in the Netherlands. Soc Sci Med 2000;51:243-9.

23 Leggett S, van der Zee-Neuen A, Boonen A, et al. Content validity of global measures for at-work productivity in patients with rheumatic diseases: an international qualitative study. Rheumatology 2016;55:1364-73.

24 WHO. International classification of functioning, disability, and health. Geneva: ICF, 2001.

25 Hedley D, Uljarević M, Cameron L, et al. Employment programmes and interventions targeting adults with autism spectrum disorder: a systematic review of the literature. Autism 2017;21:929-41.

26 Boonen A, Boone C, Albert A, et al. Contextual factors influence work outcomes in employed patients with ankylosing spondylitis starting etanercept: 2 -year results from AS@Work.Rheumatology 2018:57:791-7.

27 Rodrigues Manica S, Sepriano A, Ramiro S, et al. Work participation in spondyloarthritis across countries: analysis from the ASAS-COMOSPA study. Ann Rheum Dis 2018;77:1303-10.

28 van der Zee-Neuen A, Putrik P, Ramiro S, et al. Large country differences in work outcomes in patients with RA - an analysis in the multinational study COMORA. Arthritis Res Ther 2017;19:216.
29 Stolwijk C, Castillo-Ortiz J-D, Gignac M, et al. Importance of contextual factors when measuring work outcome in ankylosing spondylitis: a systematic review by the OMERACT worker productivity group. Arthritis Care Res 2015;67:1316-27.

30 Tang K, Escorpizo R, Beaton DE. Measuring the impact of arthritis on worker productivity: perspectives, methodologic issues, and contextual factors, 2011: 1776-90.

31 Nielsen SM, Tugwell P, de Wit MPT, et al. Identifying provisional generic contextual factor domains for clinical trials in rheumatology: results from an OMERACT initiative. J Rheumatol 2019:46:1159-63.

32 OMERACT. Chapter 4. developing core domain sets. OMERACT Handbook. Available: https://omeracthandbook.org/handbook2019

33 Donoghoe MW, Gebski V. The importance of censoring in competing risks analysis of the subdistribution hazard. BMC Med Res Methodol 2017;17:52.

34 Reilly MC, Zbrozek AS, Dukes EM. The validity and reproducibility of a work productivity and activity impairment instrument. Pharmacoeconomics 1993;4:353-65.

35 Verstappen SMM, Lacaille D, Boonen A, et al. Considerations for evaluating and recommending worker productivity outcome measures: an update from the OMERACT worker productivity group. J Rheumatol 2019;46:1401-5.

36 Moher D, Hopewell S, Schulz KF, et al. Consort 2010 explanation and elaboration: updated guidelines for reporting parallel group randomised trials. J Clin Epidemiol 2010;63:e1-37. 